\title{
RESENHA
}

\section{Olhando para as origens e rearticulando o presente: a Associação Internacional dos Trabalhadores (AIT) retorna ao debate}

\author{
Looking at the origins and rearticulating the present: the \\ Workers' International Association returns to the debate
}

Crystiane Peres

Universidade Federal de Santa Catarina (UFSC) Mestranda do Programa de Pós-Graduação em História crystianeperes@gmail.com

MUSTO, Marcello (org.). Trabalhadores, Uni-vos!: antologia política da I Internacional. São Paulo: Boitempo, 2014, 333p. 
A publicação no Brasil de Trabalhadores, Uni-vos!: antologia política da I Internacional no final de 2014 por uma editora de grande alcance, bem como todos os esforços realizados para garantir lançamento e divulgação da obra no meio acadêmico ${ }^{1}$ e sindical, se tratou de algo de destaque. Apesar de sua importância primordial na história das lutas e resistências operárias, a Associação Internacional dos Trabalhadores (AIT), ou como ficou conhecida posteriormente Primeira Internacional, não era alvo de reflexão aprofundada há alguns anos. Neste sentido, a iniciativa de Marcello Musto ${ }^{2}$ em organizar tal publicação deve ser destacada.

O olhar para uma organização depois de um longo período de "esquecimento" se comprova pela análise das próprias referências bibliográficas consultadas por Musto, que recorre a materiais publicados predominantemente até os anos 60 e 70 do século passado. Esse silêncio temporário em relação a um evento histórico de tão relevante expressão como a AIT não está, de forma alguma, ligado simplesmente a um esgotamento do tema nos meios de interesse, mas é fruto de aspectos políticos e sociais que marcaram a conjuntura.

$\mathrm{O}$ avanço do neoliberalismo nas últimas décadas do século $\mathrm{XX}$ trouxe impactos para a classe trabalhadora em todo o mundo e intensificaram a exploração e a precarização em países mais pobres, acarretando em perdas de direitos adquiridos com árduas lutas. Aliado às mudanças nas formas de produção, o ideário neoliberal atingiu a organização dos trabalhadores, provocando um abalo das estruturas tradicionais e uma perda de sua capacidade de mobilização após o impulso verificado no final dos anos 70 e em toda década de 80 no caso brasileiro ${ }^{3}$. Podemos afirmar que a ofensiva do capital

1 O livro foi lançado no Encontro Internacional "150 anos da Associação Internacional dos Trabalhadores" realizado em novembro de 2014 na Unicamp. O evento foi organizado pelo Professor Ricardo Antunes, do Instituto de Filosofia e Ciências Humanas (IFCH), que, segundo relato feito neste Encontro, também teve participação na organização de eventos de lançamento do livro e de debates sobre a AIT em universidades brasileiras no mesmo período. Intervenção de Marcello Musto no Encontro Internacional disponível em: https://www.youtube.com/watch?v=A1h5kMEX2EA

${ }^{2}$ Marcello Musto é italiano, nascido em Nápoles em 1976, e atualmente é professor do Departamento de Sociologia da York University, Canadá. É doutor em filosofia e política pela Universidade de Nápoles e em filosofia pela Universidade de Nice. Tem como foco de seus estudos a produção de Marx e Engels, o pensamento socialista e história do movimento operário. Importante destacar o alcance de seus estudos, já traduzidos em 16 línguas.

${ }^{3}$ Assim como diferentes linhas de reflexão, consideramos a questão da capacidade organizativa da classe trabalhadora um tema de grande complexidade e que, sem dúvida, envolve muitos elementos que devem ser problematizados. No entanto, há necessidade de considerar os impactos específicos deste movimento verificado nos anos 90 no Brasil.

Revista Em Debate (UFSC), Florianópolis, volume 16, p. 116-121, 2016. ISSNe 1980-3532 
através destas medidas foi o mote dos anos 90, quando o falso debate sobre o fim dos empregos foi amplamente posto no país ${ }^{4}$.

Nesse sentido, uma publicação como a organizada por Marcello Musto - além dos eventos de debate - deve ser valorizada desde seu ponto de partida, apenas enquanto propósito de reavivar o debate sobre a história e as potencialidades da organização de trabalhadores. Todavia, voltar as atenções para a AIT considerando seu ineditismo, as dificuldades práticas enfrentadas por trabalhadores que dela fizeram parte (comunicação, deslocamentos, financeiras, etc.), a atuação diante da proibição de organização verificada em diferentes países à época e, sem dúvida, o que ela representou para a construção do socialismo na história mundial, faz os méritos se multiplicarem.

Soma-se às virtudes da obra a apresentação feita de início, já no Prólogo, da relação de acervos e principais documentações originais disponíveis atualmente sobre a AIT, além de produções posteriores. Enfim, trata-se de peça de grande valia para estudiosos do movimento operário iniciarem um caminho de pesquisa sobre a AIT ou para aqueles que desejam conhece-la com vistas à reflexão para atuação política na atualidade, aliás sendo esta a principal motivação para a publicação do livro, conforme aponta Musto:

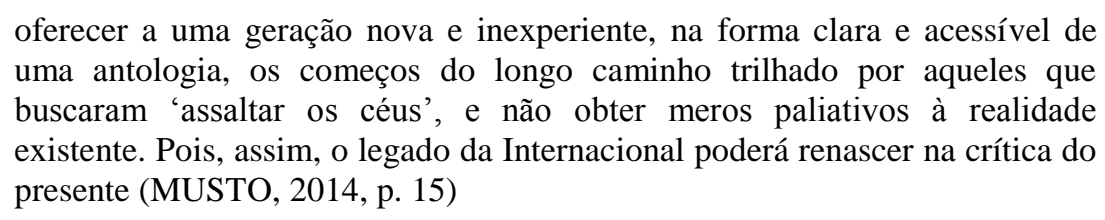

Além desses aspectos apontados como diferenciações da obra Trabalhadores Uni-vos!, devemos ressaltar mais um elemento e, certamente, o mais importante deles: o efetivo protagonismo dos trabalhadores na construção e condução dos rumos da Primeira Internacional. Segundo o próprio Marcello Musto - de forma mais enfática em sua intervenção em eventos de lançamento do livro ${ }^{5}$, mas também na própria publicação - o momento histórico nos permite superar o que ele chamou de uma abordagem de influência soviética que aponta Karl Marx como único responsável pela existência da AIT. A forma como Musto optou por apresentar a Associação, recorrendo a materiais

\footnotetext{
${ }^{4}$ Para exemplificar este movimento podemos citar os esforços do economista americano Jeremy Rifkin que com o best seller $\mathrm{O}$ fim dos empregos pautou a abordagem conservadora sobre o mundo do trabalho e influenciou o senso comum.

${ }^{5}$ Ver Nota de rodapé 2.

Revista Em Debate (UFSC), Florianópolis, volume 16, p. 116-121, 2016. ISSNe 1980-3532
} 
originais e em grande parte deles resoluções debatidas e aprovadas em Congressos da Internacional, proporcionam uma aproximação que valoriza o que efetivamente estava posto na organização. Trabalhadores dos mais diversos agrupamentos e com diferentes perspectivas políticas construíram a AIT. "Internacionalistas, muitos deles trabalhadores comuns", nas palavras de Musto, se dedicaram a reflexão em suas organizações de base e debateram suas teses em congressos anuais, nos quais Marx sequer esteve presente (com exceção de um único Congresso).

A abordagem da AIT a partir da análise de suas resoluções congressuais permite conhecer trabalhadores que não tiveram seus nomes marcados na história do movimento operário, mas que foram fundamentais para formulações da Associação e consequentemente para o pensamento socialista como o vemos hoje. Ademais, permite também conhecer a complexidade e a variedade de temas abordados pela organização, o que também é valorizado a partir do critério para escolha dos textos apresentados na publicação. Musto ressalta que "a escolha dos textos neste volume tem uma finalidade precisa: mostrar a configuração econômica e política da sociedade futura que os membros da Internacional buscavam alcançar” (Ibid, p. 15).

Esta atenção à reflexão dos trabalhadores inverte, inclusive, uma ideia propriamente burguesa que exige um reconhecimento formal/institucionalizado para a participação política, possibilidade esta vetada aos trabalhadores considerando suas restrições de acesso à educação impostas pelo Estado ou pelos patrões. Sendo assim, o livro traz não apenas textos com temáticas que podem ser consideradas clássicas da abordagem operária como a própria organização dos trabalhadores, greves, trabalho de mulheres e crianças, jornada de trabalho, entre outros, mas também reflexões sobre o uso da maquinaria e seus impactos, crédito cooperativo, propriedade coletiva, educação, internacionalismo e oposição à guerra, etc.

Em grande parte deste material também é possível identificar os traços (às vezes já explícitos) dos embates do que posteriormente se constituiu nas divergências entre as perspectivas anarquistas e comunistas/marxistas. No entanto, mais uma vez com uma escolha coerente, Musto opta por não abordar tão incisivamente este debate que, segundo ele, já foi exaustivamente tratado - ainda que não esteja esgotado. Sem dúvida, a própria apresentação dos textos de autoria de trabalhadores de diferentes vertentes políticas e de grandes nomes das duas correntes - Mikhail Bakunin e Karl Marx remetem ao embate político no interior da Internacional, mas a multiplicidade de temas, 
propostas e autores apresentados apontam que a Internacional não se esgotou nesta discussão.

Seria importante apenas considerar uma pequena ressalva, justamente no que ele se aproxima destas divergências políticas. Apesar dos coerentes apontamentos da complexidade da Internacional, de sua amplitude e da importância da participação de sujeitos comuns, a abordagem sobre a atuação de Karl Marx no âmbito do Conselho Geral e sua capacidade de direcionar decisões em partes se contradiz com a proposta que se quer construir no livro. O tópico "O homem certo no lugar certo" (Ibid, p. 21) reproduz o tom de parte significativa da abordagem marxista da Internacional. Afirmações como "a tarefa política de fazer conviver todos esses ânimos na mesma organização [...] foi indiscutivelmente obra de Marx" (Ibid, p. 23) e algumas outras apresentadas no livro são opostas ao caráter da Internacional e definitivamente desconsidera o esforço e interesse geral da AIT pela construção de uma iniciativa coletiva e de solidariedade. A exaltação aos documentos escritos por Marx no Conselho Geral da AIT indica inclusive uma alteração do propósito do Conselho Geral por ele, o que deve ser considerado em uma análise da organização.

Por todos os elementos apontados aqui, Trabalhadores, Uni-vos! tem uma importância relevante no atual cenário dos estudos do movimento operário. Contudo, seus méritos não se encerram por seu valor no meio acadêmico. A ofensiva capitalista vivenciada no Brasil nos anos 90 e acirrada nos últimos anos exige uma profunda reflexão sobre as formas de atuação e mais diretamente da resistência da classe trabalhadora, mas também com a retomada da perspectiva de uma nova sociedade. Olhar e buscar sentir de alguma forma o fervor das lutas no século XIX pode ser fundamental nesta atual encruzilhada.

\section{Referências}

FREYMOND, Jacques. La Primera Internacional. Vols I e II. Madrid: Edita Zero, 1973.

GUILLAUME, James. L'Internationale: documents et souvenirs. Vol. I: 1864-1872. Paris: Éditions Gérard Lebovici, 1985.

MALON, Benoît. A Internacional: sua história e seus princípios. São Paulo: Imaginário, 2014.

MUSTO, Marcello (org.). Trabalhadores, uni-vos!: antologia política da I Internacional. São Paulo: Boitempo, 2014, 333 p.

Revista Em Debate (UFSC), Florianópolis, volume 16, p. 116-121, 2016. ISSNe 1980-3532 
RIFKIN, Jeremy. O Fim dos Empregos. São Paulo: Makron Books, 1995, 348 p.

SAMIS, Alexandre. Negras Tormentas: o Federalismo e o Internacionalismo na Comuna de Paris. São Paulo: Hedra, 2011, 368 p. 